\title{
Professional Tennis's Constellational Response to COVID-19
}

\author{
Kyle R. King \\ Penn State Altoona
}

\begin{abstract}
Tennis's dispersed power relations have made its semiorganized response to COVID-19 "constellational" rather than hierarchical. The author uses the term "constellational" in two senses. First, what might appear to be a disorganized set of stars in the night sky can, with a bit of orientation, be tracked into discernible and more meaningful patterns. In tennis, constellations are clusters of tour events that are linked through geography, court surface, governing bodies, key sponsors, and other forms of patronage. Second, the author invoked the language of "constellations" to draw upon the popular connotation of "stars": iconic figures on- and off-court who speak and act in ways that carry outsize importance to the game's audience. This constellational set of power relations has led to conflicted messaging —only sometimes valuing public health. Both prestigious tournaments and star players have emerged as important stakeholders, as tennis assesses its future-and organizational structure-postpandemic.
\end{abstract}

Keywords: ATP-WTA merger, French Open, Novak Djokovic, Roger Federer

On March 8, 2020, a press release from the BNP Paribas Open at Indian Wells, California, announced that the event-scheduled for March 9-22-had been canceled due to a confirmed case of the novel coronavirus in the Coachella Valley. The first paragraph of the press release ("Indian Wells," 2020) cited "the guidance of medical professionals, the Centers for Disease Control, and [the] State of California" in helping to affirm the decision, whereas the second paragraph leaned on the credibility of a quote from "Dr. David Agus, Professor of Medicine and Biomedical Engineering at the University of Southern California." The event provided more insightful understanding of the risks of transmission at mass gatherings, more willingness to defer to the expertise of public health officials, and-quite frankly-more prescient leadership than the duly elected leaders of many nations around the world. The tournament cancellation preceded the NBA's much more highly publicized announcement of a canceled basketball game between the Utah Jazz and Oklahoma City Thunder by 3 days, and avoided the infamy of events such as the March 10 UEFA Champions League football

The author (krk5171@psu.edu) is with the Div. of Arts and Humanities, Penn State Altoona, Altoona, PA, USA. 
match between Atalanta and Valencia attended by 40,000 people in Spain, which Bergamo, Italy, mayor Giorgio Gori later likened to "una bomba biológica" ("a biological bomb") that intensified the rate of infection across pockets of Europe (Picó, 2020, para. 1).

Proactive leadership is - again, quite frankly — not often a trait associated with professional tennis. A cursory glance at the history of tennis's institutionalized leadership reveals why: There are too many proverbial cooks in the kitchen, all of whom are fighting over the restaurant's menu-and its profits. For instance, the professional game remains gender segregated at the institutional level, between the Association of Tennis Professionals (ATP) Tour for men's players and the Women's Tennis Association (WTA) Tour for women's players. National federations in Australia (Tennis Australia), France (Fédération Française de Tennis), the United Kingdom (Lawn Tennis Association), and the United States (United States Tennis Association) govern each of the game's Grand Slam tournaments. The International Tennis Federation governs the Davis and Fed Cups, assists with player rankings systems, and sanctions lower-level events around the globe. Individual tournamentsmore than 50 events on each tour during a typical year-also have owners and tournament directors, sometimes in close business relationships with individual players on tour. In addition, a growing system of "patronage" has taken hold of the game in recent years, giving corporate sponsors and marketing agencies an increased voice in how the sport is structured (Hummel \& Dyreson, 2019). As a result, there are at least seven major stakeholding bodies that must agree—or be wrestled into consent - on any substantive changes to the sport.

In this atmosphere, I argue that tennis has adopted a "constellational" rather than hierarchical approach to governance. I use the term "constellational" in two senses. First, what might appear to be a disorganized set of stars in the night sky, can, with a bit of orientation, be tracked into discernible and more meaningful patterns. Clusters of tour events that are linked through geography, court surface, governing bodies, key sponsors, and other forms of patronage could be considered tennis's "constellations." Second, I invoke the language of "constellational" to draw upon the popular connotation of "stars": iconic figures on- and off-court who speak and act in ways that carry outsize importance to the game's audience. This system of constellational leadership has been put on display throughout the COVID-19 pandemic. Sometimes consent has been won among stakeholders and decisions benefitting public health have been made. Sometimes individual stakeholders have prioritized their own messaging or financial interests to the detriment of public health. Constellational leadership has even been deployed as part of a trial message in support of restructuring some of these key stakeholdersthrough a possible merger of the ATP and WTA tours. This commentary outlines the decisions made thus far while reflecting on the uncertainty that remains.

\section{The Grand Slams}

With a bit of simplification, the top touring professional tennis calendar looks something like this: southern-hemisphere hard court tournaments in January/ February, culminating in the Australian Open; brief hard-court season in Indian Wells and Miami in March/April; European clay-court season building to the 
French Open in May/June; brief European grass-court season, culminating in Wimbledon in late May and early June; summer hard-court season in North America, culminating in the U.S. Open in late August and early September; and a final indoor hard-court season in Europe and East Asia through early November, culminating in year-end tour finals.

Each of these miniature geographically organized seasons might be thought of as a constellation. The brightest stars in the sky, around which four of these constellations are oriented, are tennis's Grand Slam events: the Australian Open, the French Open, Wimbledon, and the U.S. Open. Although the points and prize money acquired in the lead-up to these majors is critical to maintaining a professional ranking and making a living as a touring professional, for the top players, these non-Slam events serve primarily as preparatory tune-ups to the majors, at which lasting reputations are built. To cancel a Grand Slam event, then, eliminates an opportunity for tennis players to hoist their own star into the sport's firmament.

The first Grand Slam event in the schedule after Indian Wells was the French Open, originally scheduled for May 24 to June 7, 2020. On March 17, the Fédération Française de Tennis announced that they were postponing the event and rescheduling for September 20 to October 4. The press release included a selfcongratulatory quote from Fédération Française de Tennis President Bernard Guidicelli, who heralded the "difficult yet brave decision in this UNPRECEDENTED situation" ("Roland-Garros," 2020, para. 6). Other tennis stakeholders found Roland Garros's decision to unilaterally reschedule without consulting other stakeholders a presumptuous affront. During the 2-week period that Roland Garros selected, the ATP had already-scheduled events in Russia, China, France, and Bulgaria; the WTA had already-scheduled events in Japan, China, South Korea, and Uzbekistan; and the up-and-coming Laver Cup men's event was scheduled for the days immediately preceding. As New York Times sportswriter Clarey (2020a) summarized, the situation "created an ocean of bruised feelings" (para. 11) and indicated that less prestigious events on the tournament calendar-or, with more prejudicial connotations, events outside of the tour's traditional Western European and English-speaking power base-risked being swallowed unless they maneuvered aggressively.

Following the French Open's lead, the WTA event originally scheduled for Strasbourg in May posted on Twitter (WTA Strasbourg, 2020) that they intended to hold their tournament as a tune-up event for the French Open-akin to a barnacle living in a commensal relationship on a whale. "Les \#IS2O souhaitent contribuer à la renaissance du tennis et du sport valeur de lien social," the event's Twitter account broadcast, roughly translated as, "The Strasbourg 2020 tournament hopes to contribute to the rebirth of tennis and of sport in creating valuable social connections." No mention of event finances rose to the level of social media, but at least one fan replied to challenge the sentiment expressed: "Pas de tennis avant 2021 c'est beau de rêver enfin c'est à la limite de la stupidité à votre stade," roughly translated as, "No tennis until 2021. It's beautiful to dream; however, it's bordering on stupidity at your stadium," followed by the universal symbol for the wink emoji. As of mid-May, the official ATP calendar has not acknowledged the French Open's attempt to muscle in on its prescheduled tour events.

For a variety of reasons, no such ocean of bruised feelings occurred when, on April 1, Wimbledon and a number of smaller venues made a coordinated 
announcement that the entire grass-court season would be canceled. As a club sustained by private memberships and less beholden to stadium gate receipts, Wimbledon did not face the same existential financial pressures as other tournaments. Because the Lawn Tennis Association administers each of the tune-up events played in the United Kingdom in addition to Wimbledon, a joint announcement regarding all grass-court events was much easier. Perhaps most importantly, though, climate considerations limit when the grass-court surface of these events remains playable at elite levels, such that postponement to later in 2020 never seemed a serious possibility.

As of late May, the U.S. Open is currently scheduled to proceed-though if it does occur, the event will likely only be held in a radically altered form, and perhaps even in a different location, such as Indian Wells or Miami, where a number of top professionals already have private training bases where they can remain quarantined when not in competition. The United States Tennis Association converted part of its Billie Jean King National Tennis Center in Flushing Meadows to a makeshift hospital for coronavirus patients in hard-hit New York; other sections of the complex housed lunches for children in need. The United States Tennis Association has also put forth some financial aid and significant guidance for teaching professionals and recreational clubs to guide communities to a safe return to tennis, once local restrictions are lifted ("Playing Tennis Safely," 2020a, 2020b; Stone, 2020).

The Australian Open, alone among the majors in having been completed in 2020, has led the way in imagining what tennis will look like in 2021. As of early May, Tennis Australia had modeled four scenarios for the 2021 Australian Open, including the possibility of a canceled tournament. Tournament director Craig Tiley has suggested that a best-case scenario involves social distancing in stadiums, with only Australians able to enter the venue (Walton, 2020). This modeling of different possible strategies has subsequently been followed by other large-scale sporting events, biding their time to determine whether a second spike of coronavirus cases occurs in fall and winter 2020.

Looking at tournament websites for events scheduled for 2020, a few communication patterns have emerged. Most problematic are those tournament websites that remain out-of-date, offering no messaging to fans. Some tournaments have chosen to try to provide entertainment through alternative means, such as feature interviews, livestreamed workout sessions, or virtual tournaments played through tennis video games. More helpful are tournaments that have at least updated possible spectators on contingency plans-regardless of whether they have postponed until 2021, postponed with an eye toward rescheduling later in 2020 , or announced an intention to proceed with an originally scheduled date so long as feasible. Future sport communication researchers may wish to return to these announcements with an eye toward contract law and event insurance policies: the tactical decision to announce whether "we have chosen to postpone" or "we have been forced to postpone" may have liability and financial implications, in terms of ticketing refund policies, sponsorship agreements, and insurance coverage. Wimbledon has asked those season ticketholders not financially affected by the COVID-19 crisis to consider not asking for refunds, to maintain the event's long-term financial health. The ATP website has settled on a universal, studiously neutral turn of phrase that leaves agency open to interpretation: "Due to the global outbreak of COVID-19, this year's tournament will not proceed as scheduled." 


\section{What Have the Stars Said?}

In tennis, the Grand Slams provide the stages on which star players shine the brightest. Because of the individuality of tennis, and because of how tennis style seems to embody an individual's personality, tennis fandom is not determined by geography in the same way it might be for fans choosing to support the local football or baseball team. As a result, star players draw massive followings, where fans become cathected into players' actions on and off the court. Those star followings have been put to different uses. While modern athletes have traditionally understood the commercial benefits of stardom through branding and marketing opportunities, the contemporary athlete is increasingly tasked with demonstrating thoughtful civic judgment, generating new possibilities for public interaction. Stars become guiding lights, models of behavior for both fans and other players hoping not only to emulate their success, but also to emulate their artistic and active citizenship (Butterworth, 2014).

During COVID-19, star players have provided both admirable and more questionable leadership. Most troublingly, top men's player Novak Djokovic, citing spiritual beliefs, has repeatedly made statements at odds with mainstream scientific knowledge and recommendations. He expressed personal opposition to vaccination and speculated that he may not take a compulsory SARS-CoV-2 vaccine, if it were required to play and travel-before later walking the comment back and promising to keep an open mind (Clarey, 2020b). In a later chat with selfdescribed "alchemist" Chervin Jafarieh, Djokovic said, "I know some people that, through energetical transformation, through the power of prayer, through the power of gratitude, they managed to turn the most toxic food, or maybe [the] most polluted water into the most healing water" ("Djokovic backs," 2020, para. 4). Djokovic justified the argument by saying, "Scientists have proven in experiment that molecules in the water react to our emotions to what has been said" (para. 5). The claim is, of course, unfounded. Yet within a week, almost 500,000 people had viewed the chat. One of tennis's top stars espousing dangerous unscientific messaging has the potential to upend public willingness to follow best practices laid out by those with epidemiological and medical expertise. ${ }^{1}$

More commonly, top players have followed the playbook for wealthy athletes: they have donated financially to local causes and to a fund for lower ranked touring pros who rely upon the week-to-week income of tournament play. The fund was enacted as a rare gesture involving all four Grand Slams, the International Tennis Federation, and both the ATP and WTA tours ("Tennis rallies," 2020). Nevertheless, dissension has arisen in the details, as players criticize (Tandon, 2020) how funds may be distributed and whether specific tennis players, or even tennis players as a population, should qualify as worthy recipients.

Perhaps most interesting is the way that star player Roger Federer, in the twilight of his career, has risen to the occasion of the pandemic. The Swiss native donated 1 million Swiss francs (just over \$1M USD) to families affected by the coronavirus in Switzerland (Chavez, 2020). He provided a voiceover to an inspiring Wimbledon video production, "We Cheer for Them," praising frontline health care workers and asking tennis fans, through the use of the first-person plural "we," to "come together by staying apart." Alongside his management group, headed by Tony Godsick, Federer put out a clear statement indicating the public health reasons (not mentioning the French Open scheduling conflict) why the 
Laver Cup, an event he has spearheaded and promoted relentlessly as men's tennis's equivalent to golf's Ryder Cup, would be postponed until 2021.

Most importantly, however, Federer posted several tweets conveying a desire for the ATP and WTA tours to unify. The language of Federer's initial tweet (2020) adopted the rhetorical tactic of litotes, or understatement: "Just wondering . . . am I the only one thinking that now is the time for men's and women's tennis to be united and come together as one?" The "just wondering" framework for the tweet understated the intention and forcefulness of the message; Roger Federer has never been a figure in tennis who has offered speculative thinking without foresight or behind-the-scenes deliberations. The quickness with which icons of the sport such as Rafael Nadal, Billie Jean King, and Simona Halep-in addition to ATP Player Council member Vasek Pospisil-agreed with the tweet affirmed that some behind-the-scenes deliberation in support of a merger may have been in the works for months (Bodo, 2020). In an episode of the No Challenges Remaining podcast discussing the possibility, tennis journalist Rothenberg (2020) speculated that the gesture intentionally leveraged Federer's popularity and influence within the star system of tennis leadership: "[I]f this is an idea that's brewing and you want someone to attach it to, there's nobody with a higher approval rating in tennis to lead this charge at this moment."

A unified ATP and WTA tour has many potential benefits. A unified tour may be able to create a sense of "player power" that tips the balance of tournament revenues away from the 50-50 tournament-player balance that currently exists to earn players a greater share of the revenue. A unified tour would be able to create a much more cohesive communications presence; currently, the ATP website and mobile streaming app are more sophisticated than the WTA's. A unified tour may be better able to lobby for increased prize money in the early rounds of Grand Slams, an important source of annual revenue for players ranked outside of the top 75 on each tour. That unified presence may also improve the players' positioning as they lobby for live event television packages. Such a change could have a ripple effect on networks such as the Tennis Channel in the United States, which has to date lobbied unsuccessfully to be included in basic cable packages on providers such as Comcast, which cost the channel access to 18 million homes in the United States (James, 2013). The more people who are able to watch tennis, presumably, the more interest in the game at the grassroots level will grow. A unified tour would also be better positioned to lobby for gender equity in terms of the scheduling of matches on premium courts at premium times, currently an issue at Grand Slams and other dualgender events. Less optimistically, a unified tour may be a pragmatic decision if both tours decide they need to cut overhead, up to and including staffing salaries.

An ATP-WTA merger is not without risks. There is no guarantee that unification will create exponential growth, despite WTA chief executive Steve Simon's insistence that a merger "makes all the sense in the world" ("Merger with," 2020). Will players lower in the ranks have more or fewer opportunities in a tour with more dual-gender events, given the limited logistical possibilities of some tennis complexes? Most importantly, any unification would need to avoid the fates that have befallen previous mergers in college sports, as when the National Collegiate Athletic Association (NCAA) allowed African American athletes and female athletes into its ranks as pipelines of talent while removing coaching and administrative opportunities for African Americans and women, or relegating them to second-class citizenship 
status (Belanger, 2016; Rhoden, 2006). Any loss of equity in the administrative ranks would reasonably be accompanied by further inequities dealt to players.

Will the proposed merger move beyond "just wondering" as worldwide tournaments resume? Discussions will likely continue, and this period without play provides a unique opportunity for consensus building, as players set aside their individual trajectories to imagine the future of the enterprise as a whole. However, communication will become more difficult once players disperse around the globe and begin to compete with each other for titles and earnings, in whatever shape the tours take in 2020 and into 2021. Tennis's constellational governance and leadership model has made it adept at adjusting to the immediate risks of the pandemic, as individual events were able to cancel and reschedule much more quickly than a unified organizational model. In addition, individual players have been able to provide support in whatever ways they see fit. Nevertheless, this disjointed structure has created a set of unintended consequences that the tours, the tournaments, and the players continue to work through. An alliance between men's and women's tours has been proposed for more than 40 years without coming to full fruition. If it happens, all stakeholders must be appeased.

To put it another way: all the stars must be aligned.

\section{Notes}

1. Since this article went into production, Djokovic attempted an exhibition tour of the Balkans, the Adria Tour, with catastrophic results. He and other players were photographed not observing social distancing expectations at dance parties and pickup basketball games. Djokovic, wife Jelena, and several other players, coaches, and family members contracted the novel coronavirus as a result of the tour. Djokovic put out an apology, although he insisted that everything he did happened "with a pure heart and sincere intentions."

\section{References}

Belanger, K. (2016). Invisible seasons: Title IX and the fight for equity in college sports. Syracuse, NY: Syracuse University Press.

Bodo, P. (2020, April 22). "Just wondering": Roger Federer's comments add fuel to ATPWTA merger debate. ESPN.com. Retrieved from https://www.espn.com/tennis/story/_ /id/29084371/just-wondering-roger-federer-comments-add-fuel-atp-wta-merger-debate

Butterworth, M. (2014). The athlete as citizen: Judgment and rhetorical invention in sport. Sport in Society: Cultures, Commerce, Media, Politics, 17(7), 867-883. doi:10.1080/ 17430437.2013 .806033

Chavez, C. (2020, March 25). Roger, Mirka Federer donate one million Swiss francs to families battling coronavirus. Sports Illustrated. Retrieved from https://www.si.com/ tennis/2020/03/25/roger-federer-donation-million-francs-coronavirus-familiesswitzerland

Clarey, C. (2020a, April 3). To safeguard its future, tennis seeks unity. Even with the French Open. New York Times. Retrieved from https://www.nytimes.com/2020/04/03/sports/ wimbledon-grand-slams-canceled.html

Clarey, C. (2020b, April 20). Novak Djokovic expresses resistance to coronavirus vaccine. New York Times. Retrieved from https://www.nytimes.com/2020/04/20/sports/tennis/ coronavirus-djokovic-vaccine-covid19.html 
Djokovic backs idea of turning "polluted water into the most healing." (2020, May 7). TENNIS.com. Retrieved from https://www.tennis.com/pro-game/2020/05/novakdjokovic-backs-idea-toxic-water-can-become-healing-molecules-healing-carillo/88710/

Federer, R. (2020, April 22). Twitter. Retrieved from https://twitter.com/rogerfederer/status/ 1252922285096423424

Hummel, B., \& Dyreson, M. (2019). From folk game to elite pastime: Tennis and its patrons. In R. Lake (Ed.), Routledge handbook of tennis: History, culture, and politics (pp. 19-28). Oxon and New York: Routledge.

Indian Wells' BNP Paribas Open cancelled due to local coronavirus case. (2020, March 8). TENNIS.com. Retrieved from https://www.tennis.com/pro-game/2020/03/2020-indianwells-bnp-paribas-open-cancelled-coronavirus-covid19/87896/

James, M. (2013, September 4). Tennis Channel loses bid for new hearing in Comcast dispute. Los Angeles Times. Retrieved from https://www.latimes.com/entertainment/ envelope/cotown/la-et-ct-tennis-channel-comcast-dispute-20130904-story.html

Merger with ATP "makes all the sense in the world"-WTA chief Steve Simon. (2020). ESPN.com. Retrieved from https://www.espn.com/tennis/story/_id/29141352/mergeratp-makes-all-sense-world-wta-chief-steve-simon

Picó, D. (2020, March 25). Gori (alcalde de Bérgamo): "El Atalanta-Valencia fue una bomba biológica." Marca. Retrieved from https://www.marca.com/futbol/valencia/ 2020/03/25/5e7b106c22601d35238b4595.html

Playing tennis safely: Facility and programming recommendations. (2020a, April 22). USTA. Retrieved from https://www.usta.com/en/home/stay-current/national/playingtennis-safely--facility-and-programming-recommendations.html

Playing tennis safely: Player tips and recommendations. (2020b, April 22). USTA. Retrieved from https://www.usta.com/en/home/stay-current/national/usta-statement-on-safetyof-playing-tennis-during-the-covid-19-v.html

Rhoden, W. (2006). Forty million dollar slaves: The rise, fall, and redemption of the black athlete. New York, NY: Random House.

Roland-Garros 2020: From 20th Sep to 4th Oct. (2020, March 17). Retrieved from https:// www.rolandgarros.com/en-us/article/tournament-2020-coronavirus-rescheduled-2aseptember-4-october

Rothenberg, B. (2020, April 22). Episode \#253: The dudes wanna merge now? (with Raheem Abulleil). No Challenges Remaining [Podcast]. Retrieved from https:// nochallengesremaining.podbean.com/e/episode-253-the-dudes-wanna-merge-now-withreem-abulleil/

Stone, L. (2020, May 19). What guidelines should we follow to reopen tennis with Andy Findlay. Parenting Aces [Podcast]. Retrieved from https://parentingaces.com/whatguidelines-should-we-follow-to-reopen-tennis-with-andy-findlay/

Tandon, K. (2020, April 27). Thiem opposes lower-ranked player relief fund; wants to give elsewhere. TENNIS.com. Retrieved from https://www.tennis.com/pro-game/2020/04/ dominic-thiem-opposes-funding-lower-players-djokovic-nadal-federer/88547/.

Tennis rallies together for player relief program. (2020, May 5). International Tennis Federation. Retrieved from https://www.itftennis.com/en/news-and-media/articles/ tennis-rallies-together-for-player-relief-programme/

Walton, D. (2020, May 6). No Aust Open tennis "worst-case" prospect. Yahoo! Sport. Retrieved from https://au.sports.yahoo.com/no-aust-open-tennis-worst-case-prospect041507121--spt.html

WTA Strasbourg. (2020, April 29). Twitter. Retrieved from https://twitter.com/WTA_ Strasbourg/status/1255410916885172224 